Fig.2. WOMAC pain

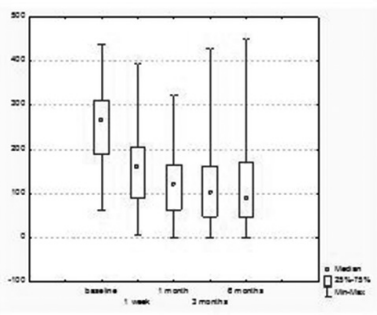

Conclusion: These results suggest that intra-articular injections of hyaluronic acid plus chondroitin sulfate in patients with knee $O A$ are efficient and safe. A single injection of the drug resulted in statistically significant reduction of pain and stiffness, reduction in NSAIDs intake, as well as improvement in patients' quality of life and function:

Disclosure of Interests: Elena Taskina Speakers bureau: Bayer, Sandoz, Boeringer-ingelheim, Ludmila Alekseeva Speakers bureau: Bayer, Boeringer-ingelheim, Gedeon-Richter, Servier, Natalia Kashevarova: None declared, Evgenia Sharapova: None declared, Ekaterina Strebkova: None declared, Sergey Anikin: None declared, Lena Zonova Speakers bureau: Sandoz, Pfizer, Abbvie, Novartis, Bayer, Tatiana Raskina: None declared, Elvira Otteva Speakers bureau: Pfizer, Abbvie, Novartis, Aleksandr Lila Speakers bureau: Sandoz, Pfizer, Abbvie, Novartis, Bayer

DOI: 10.1136/annrheumdis-2019-eular.4639

\section{AB0812 PAIN CATASTROPHIZING SCORE AND GAIT, TOGETHER WITH WOMAC, ARE ALTERED IN KNEE OSTEOARTHRITIC PATIENTS UNDERGOING ARTHROPLASTY SURGERY, COMPARED WITH PATIENTS FOLLOWING CONSERVATIVE TREATMENT. PRELIMINARY RESULTS FROM HOLOA PROJECT}

Laura Tío ${ }^{1}$, Francisco Castro ${ }^{1,2}$, Simone Tassani ${ }^{3}$, Santos Martinez ${ }^{1,4}$, Raul Torres ${ }^{1,4}$, Raquel Arredondo ${ }^{1}$, Miguel Ángel Gónzález-Ballester ${ }^{3,5}$, Joan Carles Monllau ${ }^{1,4}$, Jérôme Noailly ${ }^{3}$, Jordi Monfort ${ }^{1,2} .{ }^{1} I M I M$, Barcelona, Spain; ${ }^{2}$ Hospital del Mar, Rheumatology service, Barcelona, Spain; ${ }^{3}$ Pompeu Fabra University, BCN MedTech, DTIC, Barcelona, Spain; ${ }^{4}$ Hospital del Mar, Orthopedic Surgery and Traumatogy service, Barcelona, Spain; ${ }^{5}$ ICREA, Barcelona, Spain

Background: Osteoarthritis $(\mathrm{OA})$ is a pathology that includes several disorders that produce the same symptomatology: pain, functional impotence and inflammation. It lacks therapies that act over the physiopathology of the disease, rather than over the symptoms [1]. Patients' phenotyping is essential to describe the disorders underlying the OA symptoms, and would allow applying treatments to the altered conditions, in a personalized medicine approach.

Objectives: The HOLOA project aims to design a multivariate model that allows classifying knee $\mathrm{OA}$ patients according their characteristics in 3 areas: pain, clinical/morphological characteristics and articular defects. The present work is a preliminary study with the aim to describe the clinical and gait dynamics differences between $O A$ patients classified by treatment: conservative (CNS) vs arthroplasty surgery (ART).

Methods: Prospective study of OA patients graded 2-3 in KL scale and classify by treatment. Both groups are paired by genre, age, and BMI. The studied variables are: WOMAC index (Pain (Wp), Stiffness (Wst) and Function (Wf), Hospital Anxiety and Depression Scale (HADS), London Chest Activity of Daily Living scale, Modified Baecke Physical Activity Questionnaire, Pain Catastrophizing Score(PCS), pain threshold (according to the extended peripatelar map of Arent-Nielsen) pain sensitization at the tibia anterior surface, pain temporal summation (these 3 parameters are measured with the use of an algometer [2]), ultrasound measurement of synovial hypertrophy and effusion, and gait analysis (with Helen Hayes marker protocol. Inverse dynamic analysis was performed to compute the reaction forces and torques of the $\mathrm{OA}$ and control leg [3]). Multivariate analysis of variance was performed for the treatment, genre, age and BMI.

Results: This study was performed with the data of the 70 patients recruited to date. They are classified as shown in Table 1.

\begin{tabular}{lcc}
\hline Variable & Category & N \\
\hline Gender & Male & 28 \\
& Female & 42 \\
Age & $60-67$ & 29 \\
& $68-75$ & 41 \\
BMl & $25.5-29.9$ & 30 \\
& $>30$ & 40 \\
Treatment & CNS & 44 \\
& ART & 26 \\
\hline
\end{tabular}

Only treatment factor related differences are reported.

ART group present significant higher values in Wst $(p=0.012)$, Wf $(p=0.018)$, and PCS $(p=0.018)$, than CNS group (Figure 1).Differences in PCS values show interaction with BMI $(p=0.007)$ (Figure 2). Regarding the joint, number of painful sites depend on treatment and BMl group $(p=0.032)$ (Figure 3). Finally, gait study show no direct effect of the treatment, interactions are observed in the reaction forces and torques when comparing control vs OA leg, in ART and CNS group ( $\mathrm{p}=0.004$ and $\mathrm{p}=0.002$, respectively) (Figure 4).
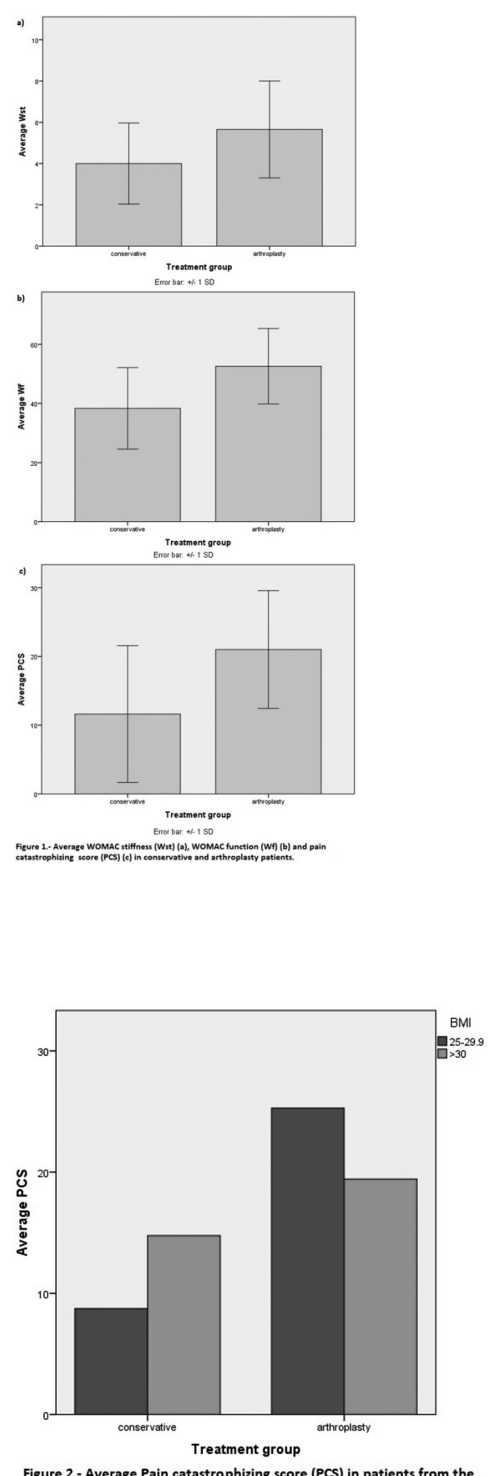

Figure 2.- Average Pain catastrophizing score (PCS) in patiens
conservative and arthroplasty group, according to their BMI. 


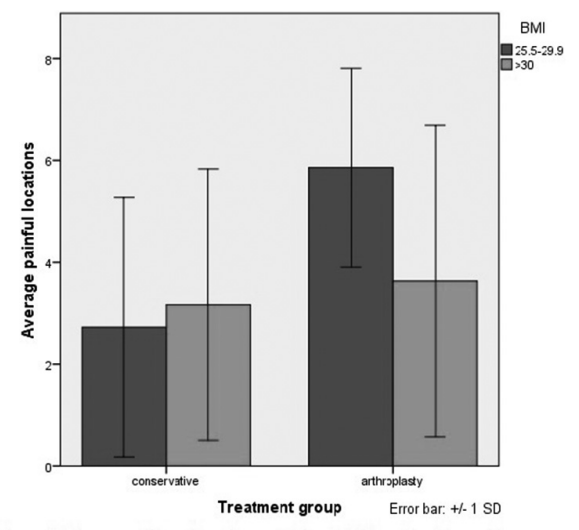

Figure 3.- Average of number of reported painful knee locations after pressure of $<4 \mathrm{Kg} / \mathrm{cm} 2$.

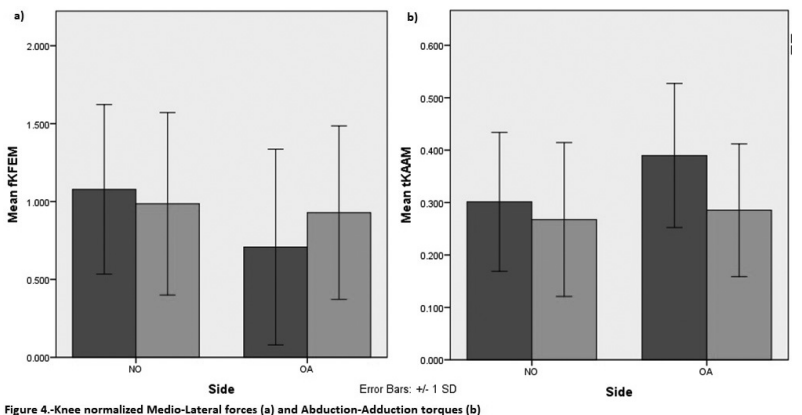

Conclusion: Although both treatment groups present the same OA radiologic grade, ART group presents significant higher stiffness and functional disability. That may affect to the gait of these ART patients, altering the forces distribution and torques between both legs. Although no differences in knee pain in life situation $(\mathrm{Wp})$ between treatment group are reported, ART group present more painful sites in the knee with pressure stimuli. Emotional component may be playing a role in the pain and illness perception, influencing the patient decision to undergo ART surgery

\section{REFERENCES}

[1] Grazina, R, Adv Exp Med Biol.1059 111-135, 2018

[2] Pujol, J et al, Pain. 158(9) 1831-1838, 2017.

[3] R.B. Davis, Hum. Mov. Sci. 10 575-587, 1991

Acknowledgement: Funds from the MICINN (HOLOA-DPI2016-80283-C2-1. $R$ and DPI2016-80283-C2-1-R (AEI/FEDER, UE), RYC-2015-18888) and DTIC-UPF are acknowledged

Disclosure of Interests: Laura Tío: None declared, Francisco Castro Speakers bureau: Lilly, Simone Tassani: None declared, Santos Martinez: None declared, Raul Torres: None declared, Raquel Arredondo: None declared, Miguel Ángel Gónzález-Ballester: None declared, Joan Carles Monllau: None declared, Jérôme Noailly: None declared, Jordi Monfort Speakers bureau: Bioibérica

Procare Health

DOI: 10.1136/annrheumdis-2019-eular.5856

\section{AB0813 AN EXPERT CONSENSUS ON THE APPROPRIATE USE OF ORAL SYSADOAS FOR THE TREATMENT OF THE OSTEOARTHRITIC PATIENT IN PRIMARY HEALTH CARE: A DELPHI STUDY}

Jordi Monfort ${ }^{1}$, Benjamín Abarca ${ }^{2}$, Xavi Carné ${ }^{3}$, Sergio Giménez ${ }^{4}$, Ingrid Möller ${ }^{5}$, Montserrat Romera ${ }^{6}$, Marco Bibas ${ }^{7}$, Marianna Vitaloni ${ }^{7}$, Josep Verges ${ }^{7} .{ }^{1}$ Hospital del Mar, Barcelona, Spain; ${ }^{2}$ Centro Salud Sagrado Corazón, Lugo, Spain;

${ }^{3}$ Hospital Clínic, Barcelona, Spain; ${ }^{4}$ Centro De Salud Y Atención Primaria Limonar Málaga, Spain; ${ }^{5}$ Institut Poal de Reumatologia, Barcelona, Spain; ${ }^{6}$ Hospital de Bellvitge, L'Hospitalet de Llobregat, Spain; ${ }^{7}$ OAFI Foundation (Osteoarthritis Foundation International), Barcelona, Spain

Background: Clinical studies have demonstrated that osteoarthritic pain is linked to disability and quality of life (QoL). The therapeutic modalities in the treatment of osteoarthritis $(\mathrm{OA})$ are numerous and despite the availability of evidence-based guidelines for OA management, agreement on treatments is lacking ${ }^{1}$. Symptomatic Slow-Acting Drugs for OA (SYSA$D O A$ ), are natural compounds, used in OA treatment. Thus, there is disagreement about SYSADOAs use in clinical practice.

Objectives: Our objective was to prepare a consensus document on the appropriate use of oral SYSADOAs: chondroitin sulphate (CS), glucosamine $(G)$, diacerein(D) and the combination of $C S$ plus $G$ for $O A$ management in primary health care.

Methods: A two-round Delphi study was carried out to assess expert consensus on the appropriate use of SYSADOAS in primary care. The questionnaire validated by the expert committee ( 3 rheumatologists, 2PC physicians, 1 clinical pharmacologist) included 24 questions The Delphi panel was composed of 15 experts (10 PC physicians, 1 rheumatologist 1 traumatologist, 1 rehabilitator, 1 gynaecologist and 1 clinical pharmacologist) with extensive experience in the treatment of $O A$ and the use of oral SYSADOAs which were identify by clinical coordinator, a methodological coordinator, and four members of the Scientific Committee. Participants were asked 24 questions on SYSADOAs use. Items that reached consensus by at least $80 \%$ across both panels were included in the guidelines. The fieldwork of the study was developed for approximately 4.5 months. This study was promoted by the International Osteoarthritis Foundation (OAFI) with the support of the Spanish Ministry of Health, Social Services and Equality.

Results: Consensus statements emerged: (1)patient phenotypes affects SYSADOAs action; (2)SYSADOAs are effective in primary and secondary $\mathrm{OA}$, in the three first grade of Knee $\mathrm{OA}$, hand and hip; there is no evidence for erosive hands, shoulder, spine, and ankle OA; (3)CS, G and association can reduce pain, inflammation, improve QoL and functional capacity and have a chondroprotective effect; (4)CS and D can reduce synovial membrane inflammation, all oral SYSADOAs, except $D$, can decrease cell death and the enzymes responsible for cartilage destruction (5) The maximum therapeutic efficacy is reached after 3 to 6 months; (6) SYSADOAs con be prescript to patients having comorbidities: cardiovascular risk or disease, digestive disease, hypertension, dyslipidemia, peripheral vascular disease, type 2 diabetes, and oesophageal reflux. There is disagreement in the prescription of oral SYSADOA in patients with liver and kidney disease.

Conclusion: This study sheds light on the appropriate use of oral SYSA DOAs in primary health care by providing added value to published evidence. Results based on literature evidence on efficacy and safety, the clinical experience of the panellist experts in OA treatment and the fact that OA patient is a chronic, elderly, with multiple diseases and polymedicated person. The diffusion of our results among primary health practitioners will contribute to improving $\mathrm{OA}$ patient management protocols to ensure a personalized treatment to $\mathrm{OA}$ patients and to ameliorate their QoL.

\section{REFERENCES}

[1] Ethgen $O$, Reginster JY. Degenerative musculoskeletal disease. Ann Rheum Dis 2004:63:1-3.

Disclosure of Interests: Jordi Monfort Speakers bureau: Bioibérica Procare Health, Benjamín Abarca: None declared, Xavi Carné: None declared, Sergio Giménez: None declared, Ingrid Möller: None declared, Montserrat Romera: None declared, Marco Bibas: None declared, Marianna Vitaloni: None declared, Josep Verges: None declared DOI: 10.1136/annrheumdis-2019-eular.4193

\section{$\mathrm{AB} 0814$ INDIVIDUAL AND SOCIAL FACTOR CAN INFLUENCE THE QUALITY OF LIFE OF KNEE OA PATIENTS: A SYSTEMATIC REVIEW}

Josep Verges ${ }^{1}$, Marianna Vitaloni ${ }^{1}$, Marco Bibas ${ }^{1}$, Rosa Sciortino ${ }^{2}$, Maritza Quintero ${ }^{2}$, Jordi Monfort ${ }^{3}$, Francisco de Abajo $^{4}$, Patrick du Souich ${ }^{5}$, Ingrid Möller ${ }^{6}$, Elizabeth Oswald ${ }^{1}$, Marco Matucci-Cerinic ${ }^{7}$, Guy Eakin $^{8}$, Angie Botto-van Bemden $8 .{ }^{1}$ OAFI Foundation (Osteoarthritis Foundation International), Barcelona, Spain; ${ }^{2}$ Universidad de los Andes, Merida Venezuela (Bolivarian Republic); ${ }^{3}$ Hospital del Mar, Barcelona, Spain; ${ }^{4}$ Alcalá University, Alcalá de Henares, Spain; ${ }^{5}$ University of Montreal, Montreal, Canada; ${ }^{6}$ Institut Poal de Reumatologia, Barcelona, Spain; ${ }^{7}$ University of Florence, Firenze, Italy; ${ }^{8}$ ARTHRITIS FOUNDATION, Atlanta, United States of America

Background: Knee $\mathrm{OA}(\mathrm{KOA})$ is the most common form of chronic join disease and bears more responsibility than any other disease for disability ${ }^{1}$. It associates with remarkable functional restrictions due to pain. The limitations in activity caused by KOA seriously affect social relationships, emotional well-being, reducing the quality of life (QoL) of patients. 